\title{
Purposeful Pedaling: Analyzing MS 150 Participant Behavior
}

\section{Elizabeth A. Gregg}

(Department of Leadership, School Counseling, and Sport Management, University of North Florida, Jacksonville, Florida, USA)

David A. Pierce

(Department of Kinesiology, Indiana University-Purdue University Indianapolis, Indiana, Indianapolis, USA)

Kristi M. Sweeney

(Department of Leadership, School Counseling, and Sport Management, University of North Florida, Jacksonville, Florida, USA)

Jason W. Lee

(Department of Leadership, School Counseling, and Sport Management, University of North Florida, Jacksonville, Florida, USA)

\section{Introduction}

Approximately \$316 billion dollars were donated to charitable organizations in 2012, representing a 3.5\% year-over-year growth rate (Giving USA Foundation, 2013). Charity sport events have become a prevalent and proven resource development strategy for non-profit organizations (Bennett, Mousley, Kitchin, \& Ali-Choudhury, 2007; Filo, Funk, \& O’Brien, 2008; 2009; Scott \& Solomon, 2003). Special events that involve an element of physical activity have become an increasingly popular means of revenue generation for non-profit organizations (Higgins \& Lauzon, 2003). Organizations’ attempt to achieve multiple goals through hosting charity events, which include generating event publicity, developing relationships with sponsors, raising awareness about a given cause, creating a population of participants that are highly invested in 
charity based sporting events, and encouraging community involvement (Ruperto \& Kerr, 2009).

Understanding participant behavior is vital to charitable organizations’ ability to reach their strategic goals. Coghlan and Filo (2013) note that sport based philanthropic activities are beneficial because of their dual appeal to people’s connection to a cause and their desire for physical activity (Coghlan \& Filo, 2013). Given the potential revenue generation derived from special events, it is critical for non-profit organizations to understand the motives of event participants and to seek feedback from participants specific to fundraising measures in order to evaluate effectiveness. This information allows for the development of strategic marketing and development initiatives capable of maximizing participant awareness and engagement with a given cause thereby driving philanthropic giving.

The purpose of this study was to explore factors affecting participant/rider awareness, attraction, and attachment to the MS 150 charitable bike ride by applying the Psychological Continuum Model (PCM) developed by Funk and James (2001; 2006). Driven by past research, we sought to provide greater insight into the factors that contribute a participant's personal attachment to a sport charity event (Filo, Funk, \& O’Brien, 2008; 2009; Filo Groza \& Fairley, 2012). Secondly, we identified behavioral patterns and demographic profiles that can help predict fundraising effectiveness through the use of regression analysis. This inquiry represents essential strides in enabling non-profit organizations, specifically those utilizing sport-based

This is the author's manuscript of the article published in final edited form as:

Elizabeth A. Gregg, David A. Pierce, Kristi M. Sweeney, \& Jason W. Lee. (2015). Purposeful pedaling: analyzing MS 150 participant behavior. International Journal of Event and Festival Management, 6(3), 269-281. http://doi.org/10.1108/IJEFM-04-2015-0020 
charity events, to reach potential donors, enhance event attendance, and most importantly, to predict and improve fundraising effectiveness.

\section{Theoretical Framework}

The theoretical framework of the current research employed Funk and James' (2001; 2006) Psychological Continuum Model (PCM). In their critical review of sport consumer typologies, Stewart, Smith, and Nicholson (2003) reported the PCM was a complex system of analysis for researchers interested in understanding the dynamic process of fan engagement, and how to move sport consumers to the stage of allegiance. The PCM has been successfully used in a number of studies focusing on charitable sporting events (Filo, Funk, \& O’Brien, 2008; 2009; Filo Groza \& Fairley, 2012). The PCM postulates that social situational and individual factors interact and produce loyalty in sport consumers. According to Funk and James (2001) "the model represents a cognitive approach that places existing fan behavior theory and research under one conceptual umbrella” (p. 121).

Within the PCM, there are four levels of participant involvement including awareness, attraction, attachment, and allegiance that exist on a vertical continuum (Funk \& James (2001; 2006). During the initial stage of attraction, an individual learns that particular teams, events, or sports exist, but have not developed loyalty to a given entity. According to Filo, Funk, and O’Brien (2008), “the awareness process occurs through socialization and leads to awareness outcomes such as the knowledge that a sporting event exists” (p. 503). In the attraction stage, Funk \& James (2001; 2006) postulate that

This is the author's manuscript of the article published in final edited form as:

Elizabeth A. Gregg, David A. Pierce, Kristi M. Sweeney, \& Jason W. Lee. (2015). Purposeful pedaling: analyzing MS 150 participant behavior. International Journal of Event and Festival Management, 6(3), 269-281. http://doi.org/10.1108/IJEFM-04-2015-0020 
individuals develop a meaningful connection to a sport event, team, or organization.

Individuals move to the final stage of the PCM once the individual has developed a sense of devotion to the sport organization or activity. Allegiance to an event or cause can result in desirable consumer attributes such as brand loyalty and a high level of organizational commitment.

\section{Motivational Factors}

Various reasons contribute to sport enthusiasts taking part in charity based sport events. Bennett, Mousley, Kitchin, and Ali-Choudhury (2007) identified three categories of drivers for sport participation that include sport, fitness, and cause-related motives. Those motivated to engage in sport endeavors understand that through involvement, they will experience pleasure, stress-reduction, weight control, enhanced fitness levels, and physical exhilaration (Haskell, 1987; Lamont \& Kennerly, 2012; Linder \& Kerr, 2001;Ryan et al., 1997). People that are motivated to engage based on cause-related motives "might be influenced to participate in an event more by their levels of personal psychological involvement with the act of supporting the charity or charities affiliated with the event than by any other consideration” (Bennett et al., 2007, p. 59).

The accomplishment of a particular goal a personal achievement also drives people to participate in charity sporting events. Taylor and Shanka (2008) indicated that success in a given sport was one of the most important attributes of individuals involved in charity based sporting events. This finding is similar to that of Funk, Mahony, and Ridinger (2002), who determined exhibitionism, personal competitive drive, and the

This is the author's manuscript of the article published in final edited form as:

Elizabeth A. Gregg, David A. Pierce, Kristi M. Sweeney, \& Jason W. Lee. (2015). Purposeful pedaling: analyzing MS 150 participant behavior. International Journal of Event and Festival Management, 6(3), 269-281. http://doi.org/10.1108/IJEFM-04-2015-0020 
desire to engage socially with individuals with similar interests were strong motivators participants.

An additional motive for participant involvement in sport related philanthropic events is connected to social interaction. The desire to interact in a social setting with individuals that value sport, fitness, and a healthy lifestyle is a commonly reported driver of charity sport participation (Hendricks \& Peelen, 2013; Mahoney, 2013). Bennett et al. (2007) emphasized the importance of creating an event environment that offers participants extensive opportunities for social interaction thereby encouraging repeat attendance. Linder and Kerr (2001) established that social pressure can serve as an impetus for individuals to participate. Recours, Souville, and Griffet (2004) also identified socialization with a like-minded community through sport participation to be a significant factor in motivating an individual to participate in a given event.

In addition to the general literature on charity sport event participation, there are a growing number of studies that have employed the PCM to better understand and explain participant behavior. For example, Filo, Funk, and O’Brien (2008) used the PCM in analyzing three variables. The first variable examined factors that attract an individual to complete a charity sporting event. Second, importance of charity in the decision to participate was tested. Finally, the manner in which the aforementioned characteristics influence an individual's attachment to the event, and the allegiance individual donors have to the event organization, and their cause was included. Their qualitative findings indicate that the interaction between hedonic and dispositional needs foster attraction to 
charity sporting events (Filo, Funk, \& O’Brien, 2009). Personal connection to the mission of the cause can also enhance participant feelings of attachment to an event. Lastly, participants that felt a high level of attachment reported that a sense of community emerged through participation in the event.

Building upon the work of Funk and James (2006), results stated that a participant's attachment to a given event is closely aligned with, and linked to, cause, camaraderie, and competency in a particular sport endeavor. Filo, Groza, and Fairley (2012) applied the PCM in their study of the relationship between motives for charity sport event participation, participants' beliefs about their ability to have an impact on a given cause, and attachment to the experience. Their findings suggest that individuals who believe they are making a difference in a particular cause are more attached to charity sporting events. According to the authors, this finding provided empirical support for Funk’s (2008) argument that the manner in which a supporter feels about a charitable organization increases their dedication to a given event. The more emotional connection one feels towards a cause will result in more awareness, attraction, and attachment to a particular event.

\section{Fundraising}

Given the increased number and occurrence of charity sport events, it is imperative for non-profit organizations to understand what motivates participants and

This is the author's manuscript of the article published in final edited form as:

Elizabeth A. Gregg, David A. Pierce, Kristi M. Sweeney, \& Jason W. Lee. (2015). Purposeful pedaling: analyzing MS 150 participant behavior. International Journal of Event and Festival Management, 6(3), 269-281. http://doi.org/10.1108/IJEFM-04-2015-0020 
what fundraising strategies are most effective. Appropriate marketing techniques can only be implored effectively once participant motives are understood. In this sense, motives for participation are significant given they are essential to maximizing event fundraising (Hart, 2002; Webber, 2004).

Grace (2005) explains that nonprofit organizations must establish effective development strategies that both identify and verify donor motivations. Her work identifies three attributes critical to understanding donor motivation: connection, concern, and capacity. Connection, the strongest of the three characteristics, is an individual's link and/or an emotional connection to the organization. Secondly, Grace explains that the concern can exist for an organization's mission without an individual having a direct link or emotional connections. For example, a corporation might invest in the MS150 not out of passion for the cause, but in concern and/or thoughtful recognition of the well-being of those affected by the disease. Grace (2005) writes, "Values inherent in concern may be more intellectual in their root than the values embedded in connection, but they are no less strong” (p. 27). Research on young philanthropists has revealed that issues (i.e., social, health, education, etc.) are a highly motivating factor for giving (Grace \& Wendroff, 2000). Lastly, and the weakest of the three attributes is capacity or an individual's perceived ability to give. While organizations cannot increase an individual's absolute capacity, they do have the means through strategic stewardship to increase one’s relative capacity (Grace, 2005). Organizations can also assist participants in how to execute the most effective fundraising strategies.

This is the author's manuscript of the article published in final edited form as:

Elizabeth A. Gregg, David A. Pierce, Kristi M. Sweeney, \& Jason W. Lee. (2015). Purposeful pedaling: analyzing MS 150 participant behavior. International Journal of Event and Festival Management, 6(3), 269-281. http://doi.org/10.1108/IJEFM-04-2015-0020 
Due to the seemingly pervasive marriage of corporate marketing and social responsibility, charitable organizations would be remiss to overlook the vast resources and opportunities available to sport related events. According to IEG Sponsorship Report (2013) 80\% of all sponsorship dollars in North America are directed toward sport, an 11\% increase from 2005. Corporate social (societal) marketing campaigns can serve as important company initiatives and involve matching gifts and resources to charitable causes, and furthermore are presumed to attract and retain talent employees (Cone, Feldman, \& DaSilva, 2003). Yet, it is critical that corporations engage in societal and cause marketing initiatives driven by their target market's (consumer and/or employees) high level of affinity for a social cause, event, or sport (Bloom, Hoeffler, Keller, \& Meza, 2006). Corporate campaigns can have substantial lasting impacts on non-profit organizations if the cause resonates with their employee base. Lastly, it is imperative that non-profit organizations focus on the motivations driving corporate investment.

Corporate partnerships should be evaluated based on their potential to enhance the organizational capacity for meeting critical community needs and not solely to drive funding efforts.

\section{Method}

\section{MS 150 PGA Tour Cycle to the Shore Overview}

The MS 150 is one of 100 rides sponsored by the National Multiple Sclerosis Society (NMSS), is held annually in Northeast, Florida. The event generated over \$1 million during the period of analysis largely due to corporate partners and avid cyclists.

This is the author's manuscript of the article published in final edited form as:

Elizabeth A. Gregg, David A. Pierce, Kristi M. Sweeney, \& Jason W. Lee. (2015). Purposeful pedaling: analyzing MS 150 participant behavior. International Journal of Event and Festival Management, 6(3), 269-281. http://doi.org/10.1108/IJEFM-04-2015-0020 
The Professional Golf Association (PGA) TOUR currently serves as the race's title sponsor. Participants, riding as individuals or members of teams, are required to raise a minimum of $\$ 200$ in donations in addition to nominal registration fees that are date specific and range from \$25-\$75. The additional cost associated with participation is (but is not limited to) lodging in Daytona (“Event Details,” 2013). The NMSS facilitates training rides, event day team pictures, ceremonial events, themed based rest stops, support and gear (SAG) vehicles, and post-ride meals.

Teams play a significant role, not only in the heightened sense of community within the ride but within the fundraising and development efforts. Several ride teams are sponsored by large, local businesses including but not limited to CSX, the Mayo Clinic, and the PGA TOUR. Teams are significant for several reasons. Teams are attractive to participants interested in social aspects and those drawn to the cycling community. Moreover, many members of the largest teams that participate in the MS 150 work for organizations that have matching gift programs. Interestingly, fundraising among teams has become a competition in itself. Teams work hard at raising the most money, and often recruit successful fundraisers from previous years to bolster team totals. The NMSS website offers fundraisers a suite of online tools and strategies for soliciting support from potential donors.

Because of the efficacy of team fundraising, the NMSS also attempts to foster behavioral patterns associated with attachment and allegiance under the PCM through annual fundraising competitions and rider perks. Each year, the top 50 fundraisers are

This is the author's manuscript of the article published in final edited form as:

Elizabeth A. Gregg, David A. Pierce, Kristi M. Sweeney, \& Jason W. Lee. (2015). Purposeful pedaling: analyzing MS 150 participant behavior. International Journal of Event and Festival Management, 6(3), 269-281. http://doi.org/10.1108/IJEFM-04-2015-0020 
recognized for their fundraising efforts. Top fundraisers are incentivized with tangible benefits ranging from complementary bike jerseys, access to VIP areas, and special recognition t-shirts and signage. The NMSS also attempts to foster community by organizing social activities at the conclusion of the first day of riding. On the lawn adjacent to the finish line is Tent Village. Tent Village features team-sponsored tents, free food and beverages, massages, bike service, and other event related products/services. The aforementioned strategies are essential in any effective fundraising and/or stewardship process implored by non-profit organizations.

\section{Instrument and Sample}

Data for this project derived from an electronic survey completed by participants of the 2013 MS 150. The Monday after the ride concluded, participants were emailed a 48-question survey created within SurveyMonkey® via an NMSS email. The survey was open for approximately 45 days. Each question provided the respondent with a range of potential options from which they selected the response that most closely mirrored their experience. Additionally, an open-ended “other” category in which the respondent could write in their answer was included for each question that did not contain an exaughstive list of options.

Of the respondents ( $n=222), 55.4 \%$ were male, and $44.6 \%$ were female. The majority of the sample (63.2\%) was over 45 years old. The sample was overwhelmingly Caucasian (89.1\%), college educated (68\%), employed full-time and earning $\$ 60,000$ or more (76\%), married or in a committed relationship (71\%), and homeowners (81\%).

This is the author's manuscript of the article published in final edited form as:

Elizabeth A. Gregg, David A. Pierce, Kristi M. Sweeney, \& Jason W. Lee. (2015). Purposeful pedaling: analyzing MS 150 participant behavior. International Journal of Event and Festival Management, 6(3), 269-281. http://doi.org/10.1108/IJEFM-04-2015-0020 
Nearly $42 \%$ of riders reported an annual income of over $\$ 100,000$ and $34 \%$ between $\$ 60,000-\$ 99,999$.

The instrument explored five categories of items including participant demographics. The first set of questions are related to how the individual became aware of the MS 150, which is the first item included in the PCM. For example, subjects were asked, "how do you find out about local events or activities for participation” and provided ten options and an open ended option. This allowed for a better understanding of how awareness of the event was sparked amongst participants. The most prevalent answer was family or friends. In terms of marketing the MS 150, this was an area of strength, as word of mouth (WOM) advertising is cost effective and raises awareness of the event (Sweeney, Soutar, \& Mazzarol, 2012; Trusov, Bucklin, \& Pauwels, 2009).

The second cluster of questions related to overall engagement in physical activity, and sub items that addressed attraction and attachment to the MS 150 and exercise in general. For example, subjects were asked "how many years have you been participating in the MS 150?” This item is tied to the attachment phase in the PCM. Other items related to the attachment phase were related to general exercise habits, specifically cycling. When asked "have you participated in other charity cycling events besides Bike MS" nearly $57 \%$ selected yes.

Questions related to fundraising tactics comprise the third set of questions. These items were designed to better understand what tools and strategies individuals employed in raising funds for the MS 150. In terms of the PCM, fundraising represents and

This is the author's manuscript of the article published in final edited form as:

Elizabeth A. Gregg, David A. Pierce, Kristi M. Sweeney, \& Jason W. Lee. (2015). Purposeful pedaling: analyzing MS 150 participant behavior. International Journal of Event and Festival Management, 6(3), 269-281. http://doi.org/10.1108/IJEFM-04-2015-0020 
objective measure of an individual's attachment and allegiance to an event. According to Filo, Funk, and O’Brien (2008) durability and impactfulness are outcomes of allegiance. In the current study, durability relates to the number of years an individual has been involved with the MS 150, and impactfulness is directly tied to fundraising.

Miscellaneous questions were the final section of questions. Because the survey was distributed by the NMSS, the miscellaneous items contained questions pertinent to the organizations mission, goals, and sponsorship. The items had no bearing on the results of the current research.

\section{Results}

With respect to awareness, nine out of ten participants (91.9\%) heard about the event from friends and family (65.4\%) or co-workers (26.5\%). The event's website and direct email blasts were the only other marketing communications to reach over $10 \%$ of the respondents. With respect to attraction, two-thirds of the respondents had a connection to MS through a friend, family member, or co-worker. Nearly $80 \%$ of participants indicated they completed the event on a team with family, friends, coworkers, or new acquaintances. Only 21\% prepared for the ride alone. Nearly $75 \%$ trained with friends or as part of a team to supplement their individual training. In addition to training for this particular event, 92\% of respondents reported they cycled on a regular basis. About 64\% stated participating in other non-profit related athletic events, and nearly 57\% took part in other philanthropic bike rides. However, of four major sporting events sponsored by the MS Society, 78\% only took part in the MS 150.

This is the author's manuscript of the article published in final edited form as:

Elizabeth A. Gregg, David A. Pierce, Kristi M. Sweeney, \& Jason W. Lee. (2015). Purposeful pedaling: analyzing MS 150 participant behavior. International Journal of Event and Festival Management, 6(3), 269-281. http://doi.org/10.1108/IJEFM-04-2015-0020 
Despite the prevalence of charity athletic event participation among the participants, nearly 74\% said nothing could have motivated them to raise more money. With respect to specific motives, $24.1 \%$ of participants stated raising money for the National MS Society was their primary reason for participating, while $21.4 \%$ noted the personal challenge. Comradery with friends and family was the main motivator for $12.9 \%$, while $8.9 \%$ joined because a friend or family had asked them to participate.

With respect to allegiance, respondents averaged 2.8 years participating in the event $(S D=3.4)$, and $37.1 \%$ of respondents were first-time participants. Nearly twothirds (65.5\%) indicated they would definitely return for the same event next year. Only $1.8 \%$ indicated they would definitely not return.

Binary logistic regression was utilized to determine which fundraising methods and personal demographic factors predicted the amount of funds raised $(n=191)$. The survey included five choices from which the respondents selected the amount raised. Categories included: less than \$100, \$101-\$250, \$251-\$499, \$500-\$1,000, and \$1,000 and above. Two analyses were run with $<$ or $=$ to $\$ 500$ and $<$ or $=$ to $\$ 1,000$ as the dependent variable. No statistically significant difference was evident between the dollar amounts. Because the $\$ 1,000$ is more significant for practitioners, it was selected for inclusion in this manuscript.

The inclusion of fundraising methods and demographic factors improved the ability to predict whether the participant raised over $\$ 1,000\left(\chi^{2}=83.7, p<.001\right.$; Nagelkerke $R^{2}=.522$ ). The model correctly predicted $83.8 \%$ of the cases. The fundraising

This is the author's manuscript of the article published in final edited form as:

Elizabeth A. Gregg, David A. Pierce, Kristi M. Sweeney, \& Jason W. Lee. (2015). Purposeful pedaling: analyzing MS 150 participant behavior. International Journal of Event and Festival Management, 6(3), 269-281. http://doi.org/10.1108/IJEFM-04-2015-0020 
methods included in the model incorporated personal email, social networking, NMSS online fundraising tools, letter writing, in-person asks, and hosting private fundraising events. The demographic variables included in the model were gender, ethnicity (white; minority), age (18-34; 35-44; 45-54; 55+), income (<\$60,000; \$60,000 - \$99,999; > $\$ 100,000)$, number of years participating (first year; 1-3 years; 4+ years), and distance traveled (<50 miles; $>50$ miles).

Because there was an interaction effect between the NMSS online tools and the use of social media (the NMSS online tools included social media functionality), the variance of this interaction was included in the model. Table 1 presents the results of the logistic regression. Each fundraising method, except for in-person asking, predicted a greater likelihood of raising more than $\$ 1,000$. The use of letter writing was 25 times more likely; hosting events, 13 times; personal email, 8 times; the use of NMSS online tools, 6 times; and social networking, 5 times. Additionally, those who had participated for four or more years were 6 times more likely than first-year riders to raise at least $\$ 1,000$; and those with incomes in excess of $\$ 100,000$ were four times more likely than those under $\$ 60,000$ to raise at least $\$ 100,000$.

\section{Discussion}

Given the increased number of sport charity events and the importance of donor giving in the non-profit sector, we examined the factors affecting participant motives as well as fundraising effectiveness. The results of our study present three notable theoretical implications. Our work supports previous research utilizing the PCM to test

This is the author's manuscript of the article published in final edited form as:

Elizabeth A. Gregg, David A. Pierce, Kristi M. Sweeney, \& Jason W. Lee. (2015). Purposeful pedaling: analyzing MS 150 participant behavior. International Journal of Event and Festival Management, 6(3), 269-281. http://doi.org/10.1108/IJEFM-04-2015-0020 
factors motivating individuals to participate in philanthropic sport events. Several studies (Filo, Funk, \& O’Brien 2008; 2009; 2011) suggest that social situational considerations (personal connection to the cause) can have the greatest influence on the relational significance of hedonic motives and dispositional needs on the development of both attraction and attachment, which is represented in the sample population. Two-thirds of the race participants were motivated by their personal connection to someone suffering from MS.

In addition to riders' strong connection to the cause, findings suggest participant attachment outcomes are underscored by the overwhelming presence of teams/communities. This is evident as approximately $80 \%$ of riders trained and completed the ride as a member of a team. Such findings are consistent with previous research indicating that socialization and social interaction are key motivating variables for the attraction and attachment phases of the PCM (Funk \& James, 2006; Filo, Funk, \& O’Brien, 2008; Funk, Mahony, \& Ridinger, 2002). They also provide support to Filo, Funk, and O’Brien (2008) recommendations that the PCM framework introduce communities as an additional attachment outcome.

A third theoretical implication is the physical challenge presented by the race itself. Individuals that find cycling pleasurable are well represented in the sample. Additionally, of four major sporting events sponsored by the MS Society, 78\% took part exclusively in MS 150. Of respondents, 37\% were first-time riders with 75\% cyclying as a member of a team. One of three first time riders were was motivated by the "personal

\footnotetext{
This is the author's manuscript of the article published in final edited form as:

Elizabeth A. Gregg, David A. Pierce, Kristi M. Sweeney, \& Jason W. Lee. (2015). Purposeful pedaling: analyzing MS 150 participant behavior. International Journal of Event and Festival Management, 6(3), 269-281. http://doi.org/10.1108/IJEFM-04-2015-0020
} 
challenge” of the race, and all first-time riders indicated that they were highly likely to return the following year. Preference for the event and the physical challenge presented by the 150-mile race, specifically with first-time riders, suggests attachment outcome realization. Thus, our findings validate previous studies that postulate the attraction phase of the PCM involve an interaction between hedonic motives, dispositional, and social situational variables.

In terms of fundraising effectiveness, Funk, Haugtvedt, and Howard (2000) determined individuals in the attachment and allegiance phases of the PCM are more likely to demonstrate high levels of commitment to a given organization. This finding was supported by our research; as the most loyal cyclists to the cause were also the most successful in their philanthropic efforts. Additionally, first time riders presented an opportunity for donor investment and stewardship to increase both their connection and concern for the NMSS while enhancing their attachment to the event. Grace (2005) noted that donors and/or prospective donors are most often motivated by one's connection to the cause. Two-thirds of the ride participants indicated they were motivated to ride because of their personal connection with someone suffering from MS. Participants with a personal connection to the cause, and a passion for cycling have the potential to be powerful in terms of fundraising capacity.

\section{Managerial Implications}

Participants in the MS 150 reported an overwhelming desirability to consume the sport of cycling as a member of a team. It is plausible that group training rides (sponsored

This is the author's manuscript of the article published in final edited form as:

Elizabeth A. Gregg, David A. Pierce, Kristi M. Sweeney, \& Jason W. Lee. (2015). Purposeful pedaling: analyzing MS 150 participant behavior. International Journal of Event and Festival Management, 6(3), 269-281. http://doi.org/10.1108/IJEFM-04-2015-0020 
by the NMSS or cycling teams) and team affiliations incite feelings of community among participants. Sarason (1974) described community as individual feelings of social support and belonging at a group level. Scholars have determined a sense of community can develop within specific geographic locations and/or in groups that share common interests (Kellet \& Warner, 2011; Warmer, Kerwin, \& Walker, 2013; Warner et al., 2011). In this case, common interests include the mission of the NMSS and the sport of cycling.

Because feelings of community within organizations can lead to enhanced participant retention and create feelings of attachment among participants, it is crucial to be intentional in planning ride related events that are social in nature. The NMSS stages a number of activities designed to develop and maintain a sense of community among cyclists and other people associated with the chapter. Outside of events associated with the MS 150 weekend, the NMSS also offers pre and post-ride meals and an awards ceremony approximately one month after the MS 150. These activities support the development of community among ride participants. By increasing the number of social events and training rides throughout the year, it is plausible that awareness among cyclist and those dedicated to the NMSS in Northeast Florida could increase, and engender feelings of attraction and attachment to the MS 150 (Funk \& James, 2001).

Findings also underscore the importance of WOM marketing in the awareness process. WOM is the flow of communication among consumers regarding products or services. WOM advertising in sport marketing includes consumers transferring

This is the author's manuscript of the article published in final edited form as:

Elizabeth A. Gregg, David A. Pierce, Kristi M. Sweeney, \& Jason W. Lee. (2015). Purposeful pedaling: analyzing MS 150 participant behavior. International Journal of Event and Festival Management, 6(3), 269-281. http://doi.org/10.1108/IJEFM-04-2015-0020 
"information to other consumers without the perceived influence of the sport organization” (Schwarz, 2011, p. 1664). WOM is demonstrated to be approximately 2030 times more effective than event and media marketing respectively (Trusov, Bucklin, \& Pauwels, 2009).

Findings of this study showed that about $66 \%$ of the sample reported their awareness of the MS 150 stemmed from the transfer of information from a family member or friend while $26.5 \%$ heard from a co-worker. Given the large percentage of riders informed about the race by WOM exemplifies the importance of utilizing this marketing technique in the awareness stage of the PCM. The NMSS would be well served by capitalizing on the power of WOM by continuing to distribute cause related information actively to individuals demonstrating attachment (Hogan, Lemon, \& Libai, 2004). Those persons would then be empowered to grow awareness and attraction to the MS 150 within their respective social circles and build participation. Ultimately, strategic information distribution has the potential to enhance the advancement of the mission of the NMSS through WOM.

It is arguable that the NMSS's activities associated with cause related fundraising exemplify best practices within the industry. By targeting corporate teams capable of matching donations and fostering attachment among ride participants, the NMSS regularly raises over \$1 million donations from the MS 150 alone.

The fundraising tools offered through the NMSS website that allow participants to customize their solicitation message are proven to be successful. It is advantageous that

This is the author's manuscript of the article published in final edited form as:

Elizabeth A. Gregg, David A. Pierce, Kristi M. Sweeney, \& Jason W. Lee. (2015). Purposeful pedaling: analyzing MS 150 participant behavior. International Journal of Event and Festival Management, 6(3), 269-281. http://doi.org/10.1108/IJEFM-04-2015-0020 
non-profit organizations provide tutorials and educational resources focused on the praciticality and valuableness of online tools in order to maximization revenue generation through donations. This is especially important as online giving has experienced double digit growth rates in both 2012 (10.7\%) and 2013 (13.5\%) and appear to be thriving mechanisms to drive annual giving (McLaughlin, 2013). In the current study, letter writing was the most effective means of donation collection, but nearly all of the tools recommended and offered by the organization led to more effective fundraising by participants.

While a number of the previous recommendations have focused on the acquisition of new donors, nonprofits organizations must focus their efforts on retention. According to the Fundraising Effectiveness Project (FEP) (2013), while U.S. nonprofits saw increased overall donor attrition outpaced new supporter acquisition. The same report noted that repeat donor retention rates were two times that of new donor retention. Our findings provide additional insight into the importance of repeat donor retention given the race's most effective fundraisers had reached the allegiance phase of PCM. Lastly, given 2 in 5 participants were first time riders the NMSS should focus on continued involvement and cultivation of new donor after the race to improve new donor retention. Thus, the goal of organizations like the NMSS should be to increase both repeat and new donor retention rates thereby enhancing overall fundraising effectiveness, given the acquisition on new donors is both costly and time consuming.

\section{Future Directions}

\footnotetext{
This is the author's manuscript of the article published in final edited form as:

Elizabeth A. Gregg, David A. Pierce, Kristi M. Sweeney, \& Jason W. Lee. (2015). Purposeful pedaling: analyzing MS 150 participant behavior. International Journal of Event and Festival Management, 6(3), 269-281. http://doi.org/10.1108/IJEFM-04-2015-0020
} 
While the findings coincide with other investigations of charity based sport events, a more thorough analysis would include participants from other MS 150 rides across the United States. The results of this study provide additional credibility to the effectiveness of the PCM as a tool to better understand participant behavior in a sport context. Future research should focus on developing an objective model capable of accurately gauging levels of attachment and allegiance to a given event. The complex nature of assessing how and when an individual enters the allegiance phase warrants additional examination. Additional studies employing the PCM in the context of lowintensity sport based philanthropic events such as fundraising would add credence to the framework. It is plausible that low-intensity sport events attract different demographics of individuals. These differences could shed light on the most effective means to attract potential donors to a broader range of philanthropic sport events.

\section{Conclusion}

Non-profit organizations utilize charity sport events to procure resources for the organization. The PCM provides a useful framework for understanding participant behavior from a theoretical and applied perspective. Our work supports past scholarship that has utilized the PCM to test factors motivating individuals to participate in philanthropic sport events. The results of this study validate previous studies that postulate the attraction phase of the PCM involving an interaction between hedonic motives, dispositional, and social situational variables. In addition to riders’ strong connection to the cause, the results also suggested participant attachment outcomes are

This is the author's manuscript of the article published in final edited form as:

Elizabeth A. Gregg, David A. Pierce, Kristi M. Sweeney, \& Jason W. Lee. (2015). Purposeful pedaling: analyzing MS 150 participant behavior. International Journal of Event and Festival Management, 6(3), 269-281. http://doi.org/10.1108/IJEFM-04-2015-0020 
underscored by the overwhelming presence of teams and communities. Finally, the organization has implemented best practices around fundraising as the methods promoted by the organization result in more effective fundraising. Developing retention strategies for repeat participants is critical because the most effective fundraisers were those who had reached the allegiance phase of PCM.

This is the author's manuscript of the article published in final edited form as:

Elizabeth A. Gregg, David A. Pierce, Kristi M. Sweeney, \& Jason W. Lee. (2015). Purposeful pedaling: analyzing MS 150 participant behavior. International Journal of Event and Festival Management, 6(3), 269-281. http://doi.org/10.1108/IJEFM-04-2015-0020 


\section{References}

Bennett, R., Mousley, W., Kitchin, P., \& Ali-Choudhury, R. (2007). Motivations for participating in charity-affiliated sporting events. Journal of Customer Behaviour, 6(2), 155-178.

Bloom, P., \& Hoeffler, S. Keller., K.L. \& Meza, C.E.B. (2006). How social-cause marketing affects consumer perceptions. MIT Sloan Management Review, 47(2), 49-55.

Coghlan, A. \& Filo, K. (2013). Using constant comparison method and qualitative data to understand participants’ experiences at the nexus of tourism, sport and charity event. Tourism Management, 35, 122-131.

Cone, C. L., Feldman, M. A., \& DaSilva, A. T. (2003). Causes and effects. Harvard Business Review, 81(7), 95-101.

Filo, K., Funk, D. C., \& O’Brien, D. (2008). It’s really not about the bike: Exploring attraction and attachment to the events of the Lance Armstrong Foundation. Journal of Sport Management, 22, 501-525.

Filo, K., Funk, D. C., \& O’Brien, D. (2009). The meaning behind attachment: Exploring camaraderie, cause, and competency at a charity sport event. Journal of Sport Management, 23, 361-387.

Filo, K., Funk, D. C., \& O'Brien, D. (2011). Examining motivation for charity sport event participation: a comparison of recreation-based and charity-based motives. Journal of Leisure Research, 43(4), 491-518.

This is the author's manuscript of the article published in final edited form as:

Elizabeth A. Gregg, David A. Pierce, Kristi M. Sweeney, \& Jason W. Lee. (2015). Purposeful pedaling: analyzing MS 150 participant behavior. International Journal of Event and Festival Management, 6(3), 269-281. http://doi.org/10.1108/IJEFM-04-2015-0020 
Filo, K., Groza, M. D., \& Fairley, S. (2012). The role of belief in making a difference in enhancing attachment to a charity sport event. Journal of Non-Profit \& Public Sector Marketing, 24, 123-140.

Fundraising effectiveness project (2013). Retrieved from https://bloomerang.co/blog/infographic-2013-fundraising-effectiveness-projectsurvey-report/

Funk, D. C., \& James, J. (2001). The psychological continuum model: A conceptual framework for understanding an individual's psychological connection to sport. Sport Management Review, 4, 119-150.

Funk, D. C., Mahony, D. F., \& Ridinger, L. L. (2002). Characterizing consumer motivation as individual difference factors: augmenting the Sport Interest Inventory (SII) to explain level of spectator support. Sport Marketing Quarterly, 11(1), 33-43.

Funk, D. C., \& James, J. (2006). Consumer loyalty: The meaning of attachment in the development of sport team allegiance. Journal of Sport Management, 20, 189217.

Funk, D. C. (2008). Consumer behaviour for sport and events: Marketing action. Oxford, England: Butterworth-Heinemann.

Giving USA Foundation. (2012). Annual report on philanthropy for the year 2012. Retrieved from http://www.givingusareports.org

Grace, K. S. (2005). Beyond fundraising: New strategies for nonprofit innovation and

This is the author's manuscript of the article published in final edited form as:

Elizabeth A. Gregg, David A. Pierce, Kristi M. Sweeney, \& Jason W. Lee. (2015). Purposeful pedaling: analyzing MS 150 participant behavior. International Journal of Event and Festival Management, 6(3), 269-281. http://doi.org/10.1108/IJEFM-04-2015-0020 
investment (Vol. 64). Hoboken, NJ: John Wiley \& Sons.

Grace, K. S., \& Wendroff, A. L. (2000). High impact philanthropy: How donors, boards, and nonprofit organizations can transform communities. Hoboken, NJ: John Wiley \& Sons.

Hart, T. R. (2002). ePhilanthropy: Using the Internet to build support. International Journal of Nonprofit and Voluntary Sector Marketing, 7(4), 353-360.

Haskell, W. (1987). Developing an Activity Plan for Improving Health. In: Morgan, W. and Goldston, S. (Eds.), Exercise and Mental Health, Washington, DC: Hemisphere Publishing Corporation, p. 97-119.

Hendriks, M., \& Peelen, E. (2013). Personas in action: linking event participation motivation to charitable giving and sports. International Journal of Nonprofit \& Voluntary Sector Marketing, 18(1), 60-72. doi:10.1002/nvsm.1458

Higgins, J. W., \& Lauzon, L. (2003). Finding the funds in fun runs: Exploring physical activity events as fundraising tools in the nonprofit sector. International Journal of Nonprofit and Voluntary Sector Marketing, 8(4), 363-377.

Hogan, J. E., Lemon, K. N., \& Libai, B. (2004). Quantifying the ripple: Word of mouth and advertising effectiveness. Journal of Advertising Research, 44(3), 271-280.

IEG Sponsorship Report (2013). 2013 Sponsorship Outlook: Spending increase is a double-edged sword. IEG Sponsorship Report, 1-6.

Lamont, M., \& Kennelly, M. (2012). A qualitative exploration of participant motives among committed amateur triathletes. Leisure Sciences, 34(3), 236-255.

This is the author's manuscript of the article published in final edited form as:

Elizabeth A. Gregg, David A. Pierce, Kristi M. Sweeney, \& Jason W. Lee. (2015). Purposeful pedaling: analyzing MS 150 participant behavior. International Journal of Event and Festival Management, 6(3), 269-281. http://doi.org/10.1108/IJEFM-04-2015-0020 
Linder, K., \& Kerr, J. (2001). Predictability of sport participation motivation from meta-motivational dominances and orientations. Personality and Individual Differences, 30(5), 759-773.

Mahoney, T. Q. (2013). Exploring the influence of social media on future intentions of charity sport participants (Doctoral dissertation, University of Louisville).

McLaughlin, S. (2013). Charitable giving report: How nonprofit fundraising performed in 2013. Retrieved from https://www.google.com/url?sa=t\&rct=j\&q=\&esrc=s\&source=web\&cd=1\&ved=0 CB4QFjAA\&url=https\%3A\%2F\%2Fwww.blackbaud.com\%2Ffiles\%2Fresources \%2Fdownloads\%2F2014\%2F2013.CharitableGivingReport.pdf\&ei=0$\underline{\text { EiVeWIDIGrsAXr- }}$ YD4AQ\&usg=AFQjCNG6C_lhnTRFRPlb6ytgTamG2oid8g\&bvm=bv.89947451 ,d.b2w\&cad=rja

National MS Society. (2013, May 29.) 27th annual bike MS: PGA Tour Cycle to the Shore Kickoff Ride. Retrieved from http://www.nationalmssociety.org/Chapters/FLN/About-this-Chapter/News/27thAnnual-Bike-MS-PGA-TOUR-Cycle-to-the-Shore-Ki

National MS Society. (n.d.) 201350 Phenoms. Retrieved from http://bikefln.nationalmssociety.org/site/PageNavigator/BIKE_FLN_2012_50_Ph enoms.html

National MS Society. (n.d.) Event Details. Retrieved from

This is the author's manuscript of the article published in final edited form as:

Elizabeth A. Gregg, David A. Pierce, Kristi M. Sweeney, \& Jason W. Lee. (2015). Purposeful pedaling: analyzing MS 150 participant behavior. International Journal of Event and Festival Management, 6(3), 269-281. http://doi.org/10.1108/IJEFM-04-2015-0020 
http://bikefln.nationalmssociety.org/site/PageServer?pagename=BIKE_FLN_Eve

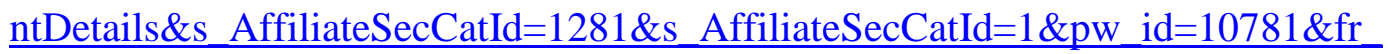
$\underline{\mathrm{id}=20286}$

Recours, R. A., Souville, M., \& Griffet, J. (2004). Expressed Motives for Informal and Club/Association-based Sports Participation. Journal of Leisure Research, 36(1), $1-22$.

Ruperto, A. R., \& Kerr, G. (2009). A study of community events held by not-for-profit organizations in Australia. Journal of Nonprofit \& Public Sector Marketing, 21, 298-308.

Ryan, R., Frederick, C., Lepes, D., Rubio, N., \& Sheldon, K. (1997). Intrinsic motivation and exercise adherence. International Journal of Sport Psychology, 28(3), 335-354.

Sarson, S. B. (1974). The psychological sense of community: Prospects for a community psychology. San Francisco, CA: Jossey-Bass.

Scott, A., \& Solomon, P. J. (2003). The marketing of cause-related events: A study of participants as consumers. Journal of Nonprofit \& Public Sector Marketing, 11(2), 43-66.

Stewart, B., Smith, A. C., \& Nicholson, M. (2003). Sport consumer typologies: a critical review. Sport Marketing Quarterly, 12(4), 206-216.

Schwarz, E. C. (2011). Word-of-Mouth. In L. E. Swayne \& M. Dodds (Eds.), 
Encyclopedia of Sports Management and Marketing (Vol. 4, pp. 1664-1666).

Thousand Oaks, CA: SAGE Reference. Retrieved from

http://go.galegroup.com.dax.lib.unf.edu/ps/i.do?id=GALE\%7CCX1959600843\&v

=2.1\&u=jack91990\&it=r\&p=GVRL\&sw=w\&asid=c7d034b95190dada8f0931bfe

$\underline{\text { b754f7 }}$

Sweeney, J. C., Soutar, G. N., \& Mazzarol, T. (2012). Word of mouth: measuring the power of individual messages. European Journal of Marketing, 46(1/2), 237-257.

Taylor, R., \& Shanka, T. (2008). Cause for event: not-for-profit marketing through participant sports events. Journal of Marketing Management, 24(9/10), 945-958.

Trusov, M., Bucklin, R. E., \& Pauwels, K. (2009). Effects of word-of-mouth versus traditional marketing: Findings from an Internet social networking site. Journal of Marketing, 73, 90-102.

Warner, S. \& Dixon, M. A. (2011). Understanding sense of community from an athletes’ perspective. Journal of Sport Management, 25, 258-272.

Warner, S., Kerwin, S., \& Walker, M. (2013). Examining sense of community in sport: Developing the multidimensional SCS' scale. Journal of Sport Management, 27(5), 349-362.

Warner, S., Shapiro, S., Dixon, M. A., Ridinger, L. L., \& Harrison, S. (2011). The football factor: Shaping community on campus. Journal of Issues in Intercollegiate Athletics, 4, 236-256. Webber, D. (2004). Understanding charity fundraising events. International Journal of

This is the author's manuscript of the article published in final edited form as:

Elizabeth A. Gregg, David A. Pierce, Kristi M. Sweeney, \& Jason W. Lee. (2015). Purposeful pedaling: analyzing MS 150 participant behavior. International Journal of Event and Festival Management, 6(3), 269-281. http://doi.org/10.1108/IJEFM-04-2015-0020 
Nonprofit \& Voluntary Sector Marketing, 9(2), 122-134.

This is the author's manuscript of the article published in final edited form as:

Elizabeth A. Gregg, David A. Pierce, Kristi M. Sweeney, \& Jason W. Lee. (2015). Purposeful pedaling: analyzing MS 150 participant behavior. International Journal of Event and Festival Management, 6(3), 269-281. http://doi.org/10.1108/IJEFM-04-2015-0020 
Table 1

Summary of logistic regression analysis for predicting fundraising effectiveness $(n=$ 191)

\begin{tabular}{|c|c|c|c|c|c|}
\hline Variable & B & S.E. & Df & Sig. & $\operatorname{Exp}(B)$ \\
\hline Gender & .225 & .471 & 1 & .632 & 1.253 \\
\hline Age & & & 3 & .140 & \\
\hline Ethnicity & -.384 & .758 & 1 & .613 & .681 \\
\hline Travel Miles & -.314 & .474 & 1 & .507 & .730 \\
\hline Years Participated & & & 2 & .020 & . \\
\hline YP (1) & 1.207 & .662 & 1 & .068 & 3.343 \\
\hline YP (2) & 1.813 & .647 & 1 & .005 & 6.132 \\
\hline Income & & & 2 & .006 & \\
\hline Income (1) & -.155 & .697 & 1 & .825 & .857 \\
\hline Income (2) & 1.435 & .622 & 1 & .001 & 8.211 \\
\hline Personal Email & 2.105 & .625 & 1 & .001 & 8.211 \\
\hline Social Networking & 1.667 & .628 & 1 & .008 & 5.298 \\
\hline NMSS Online Tools & 1.813 & .904 & 1 & .045 & 6.128 \\
\hline Letters & 3.220 & .991 & 1 & .001 & 25.027 \\
\hline Face to Face & .549 & .484 & 1 & .256 & 1.732 \\
\hline Events & 2.566 & .911 & 1 & .005 & 13.017 \\
\hline Online Tools * Social networking & -2.361 & 1.062 & 1 & .026 & .094 \\
\hline
\end{tabular}

This is the author's manuscript of the article published in final edited form as:

Elizabeth A. Gregg, David A. Pierce, Kristi M. Sweeney, \& Jason W. Lee. (2015). Purposeful pedaling: analyzing MS 150 participant behavior. International Journal of Event and Festival Management, 6(3), 269-281. http://doi.org/10.1108/IJEFM-04-2015-0020 